nhiêu nghiên cứu cũng chỉ ra tác dụng kéo dài của phương pháp cấy chỉ, hiệu quả không dừng lại sau 2 tuần, mà có thể kéo dài, hạn chế bệnh tái phát tới 6 đến 9 tháng [4]. Điều này rất phù hợp, khi mà THCSC là một bệnh mạn tính, thường xuất hiện các đợt cấp xen kẽ.

\section{KẾT LUẬN}

Cấy chỉ kết hợp bài thuốc Quyên tý thang trong điều trị đau vai gáy do THCSC có tác dụng giảm đau, tăng tầm vận động cột sống cổ và cải thiện chức năng sinh hoạt hàng ngày.

TÀI LIỆU THAM KHẢO
1. Trân Ngọc Ân (2002). Bệnh thấp khớp. Nhà xuất bản Y̛ học, Hà Nội, 193.

2. Trinh Nhu Hải và Ĺy Gia Canh (2004). Trung quốc danh phương toaan tập. Nhà xuất bản $Y$ học, Hà Nội, 746-747

3. Hoàng Bảo Châu (2010). Châm cứu học trong nội kinh, nạn kinh và sự tương đồng với y học hiện đại. Nhà xuất bản $Y$ hoc, Hà Nôii.

4. Trần Thị Thanh Hướng (2002). Cãy chỉ điều trị giảm đau trong hội chứng vai gáy. Tạp chí nghiên cứu y dược hoc cổ truyền Việt Nam, 6, 38-39.

5. Khoa $Y$ học cổ truyên, Trường Đại học $Y$ Hà Nội (2005). Bài giảng $Y$ học cố truyển. Nhà xuất bản Y học, Hà Nội, 157-158, 160-163.

6. Lê Thúy Oanh (2010). Cấy chỉ (chôn chỉ catgut vào huyệt châm cứu). Nhà xuất bản Y học, Hà Nội.

7. Bố Y Tể (2013), Quy trình kỹ thuật khám bệnh, chữa bệnh chuyên ngành Châm cứu, 607-609.

\title{
ĐĂC ĐIỂM LÂM SÀNG, CÂ̂N LÂM SÀNG CỦA BỆNH NHÂN NGộ ĐộC CẦN SA, CẦN SA TỔNG HợP TẠI TRUNG TÂM CHỐNG ĐộC BỆNH VIỆN BẠCH MAI
}

\author{
Bùi Công Thép ${ }^{1}$ Đặng Thị Xuân², Hà Trần Hưng1,2
}

\section{TÓM TẮT}

Mục tiêu: mô tả đặc điểm lâm sàng, cận lâm sàng của ngộ độc cần sa (THC) và một số cần sa tổng hợp (CSTH). Đối tượng và phương pháp nghiên cứu: nghiên cứu mô tả tiến cứu trên 48 bệnh nhân được chẩn đoán ngộ độc cấp cần sa, cần sa tổng hợp điểu trị tại Trung tâm chống độc Bệnh viện Bạch Mai từ tháng 2/2020 đến 8/2021. Kết quả: Trong số bệnh nhân nghiên cứu có 39 bệnh nhân nam $(81,3 \%)$, tuổi trung binh là $28,1 \pm 11,5$ (13-61) tuổi. Thời gian trung bình xuất hiện triệu chứng ngộ độc là $9 \pm 6,6$ phút, dạng chất sử dụng chủ yêu là sợi thực vật 54,2 $\%$, hình thức sử dụng hút thuốc chiếm $87,5 \%$, nhỏ dưới lưỡi $8,3 \%$, ăn uống $(4,2 \%)$, xịt họng $(2,1 \%)$. Các triệu chứng nhiễm độc thần kinh và tâm thần xuất hiện sớm ngay sau khi ngộ độc chóng mặt, mất điêu hòa hoặc giảm khả năng phối hợp động tác $(64,6 \%)$, kích động 47,9\%, ảo thanh, ảo thị $(45,8 \%)$, giảm ý thức, ngẩt $(33,3 \%)$, co giật $(20,8 \%)$, hoang tưởng bị hại $(16,7 \%)$, khó thở $(35,4 \%)$. Cận lâm sang: toan chuyển hóa $12,8 \%$, tiêu cơ vân cấp $10,4 \%$, hạ kali máu 47,9\%. Rối loạn nhịp tim thường gặp nhất là nhịp nhanh xoang $(35,4 \%)$, nhịp chậm xoang $(2,1 \%)$ và loạn nhịp xoang 1 bệnh nhân $(2,1 \%)$. Nhóm bệnh nhân ngộ độc cần sa tổng hợp xu hướng xuất hiện các triệu chứng rầm rộ, nguy hiểm đến tính mạng nhiều hơn so với nhóm THHC. Kết luận: Nghiên cứu cho thây các đặc điểm lâm sàng, cận lầm sàng của bệnh nhân

\footnotetext{
${ }^{1}$ Trường Đại học Y Hà Nọi,

${ }^{2}$ Trung tâm Chống độc bệnh viện Bạch Mai

Chịu trách nhiệm chính: Bùi Công Thép

Email: bscongthep@gmail.com

Ngày nhận bài: 16.8.2021

Ngày phản biện khoa học: 8.10.2021

Ngày duyệt bài: 19.10.2021
}

ngộ độc Cần sa, Cần sa tổng hợp, giúp ích cho xử trí sớm cững như tiên lượng được các biến chứng.

Tư khóa: cần sa, THC, cần sa tổng hợp, ngộ độc cấp.

\section{SUMMARY \\ CLINICAL FEATURES AND LABORATORY \\ CHARACTERISTICS OF PATIENTS WITH CANNABIS AND SYTHENTIC CANNABIS POISONINGS}

Objectives: to describe the clinical and laboratory characteristics of patient with acute poisoning of cannabis (THC) and some synthetic cannabidiol (SC) at Vietnam Poison Control Center, Bach Mai Hospital. Methods: prospective descriptive study on 48 patients diagnosed with acute cannabis (THC) and some synthetic cannabidiol (SC) poisoning treated at the Poison Control Center from January 2020 to October 2021. Results: Among the study patients, there were 39 male patients $(81.3 \%)$, the average age of the study group was $28.1 \pm 11.5(13-61)$ years old. The onset symptoms of poisoning developed $9 \pm$ 6.6 minutes after use. Abuse agents were mainly in the form of plant fibers $54.2 \%$, therefore smoking accounted for $87.5 \%$, under the tongue $8.3 \%$, eating $(4.2 \%)$, throat spray (2.1\%). Neurotoxic and psychotic symptoms appeared soon after poisoning were dizziness, ataxia or reduced ability to coordinate $(64.6 \%)$, agitation $47.9 \%$, visual hallucinations $(45.8 \%)$, decreased consciousness, syncope $(33.3 \%)$ convulsions $(20.8 \%)$, delusions of harm $(16.7 \%)$, dyspnea $(35.4 \%)$. The laboratory features included metabolic acidosis (12.8\%), acute rhabdomyolysis $(10.4 \%)$, hypokalemia $(47.9 \%)$. The most common arrhythmias were sinus tachycardia $(35.4 \%)$, sinus bradycardia $(2.1 \%)$ and sinus arrhythmia 1 patient $(2.1 \%)$. The group of patients with synthetic cannabis poisoning tended to had more seveve symptoms than 
the THC group. Conclusion: The study revealed the clinical and laboratory characteristics of patients with cannabis, synthetic cannabis poisoning, that was necessary for early management and prognosis of complications.

Keywords: cannabis (THC), synthetic cannabidiol (SC), acute poisoning.

\section{I. ĐĂT VẤN ĐỀ}

Cần sa và cần sa tổng hợp đang là vấn đề nổi trội của xã hội, cho đến nay cần sa là loại ma túy bất hợp pháp được trông, buôn bán và lạm dụng nhiều nhất. Theo tổ chức y tế thế giới (WHO) có 147 triệu người, tương đương 2,5\% dân số thế giới, sử dụng cần sa. Khiến nó là chất bất hợp pháp được trồng, buôn bán và lạm dụng nhiều nhất ${ }^{1}$. Cần sa tạo ra rất nhiều các tác dụng dược lý ở động vật và con người. Mặc dù nó được sử dụng như một loại thuốc giả trí, nhưng nó có khả nằng dẫn đển sự phụ thuộc và rối loạn hành vi và việc sử dụng nó có thể ảnh hưởng trực tiếp đến sức khỏe, tăng nguy cơ rối loạn tâm thần². Cần sa tổng hợp là một nhóm chất mới đang phát triển nhanh chóng trên khắp thế giới. Nổi lên như là một lựa chọn cho sự thay thế phổ biến cho cần sa. Nhiều chất tương tự như cần sa đang được tổng hợp có sẵn trên thị trường tiêu dùng và được bán dưới những tên gọi như: "Cỏ mỹ", "spice", "legal high", "K2","black mamba", "Bombay blue"... Thế giới đã có báo cáo xảy tra trường hợp ngộ độc hàng loạt cùng lúc, trường hợp tử vong sau khi sử dụng cần sa tổng hợp nhưng với sự đa dạng và phức tạp của các loại cần sa mới được tổng hợp trong khi hệ thống xét nghiệm phát hiện độc chất còn chưa theo kịp. Việc phát hiện sớm và chẩn đoán còn nhiều khó khằn và hạn chế. Ở Việt Nam chưa có nghiên cứu hệ thống về lâm sàng, cận lâm sàng của ngộ độc cần sa và cần sa tổng hợp. Chúng tôi thực hiện đề tài nhằm mục tiêu: mô tả đặc điểm lâm sàng, cận lâm sàng của ngộ độc cần sa $(T H C)$ và một số Cần sa tổng hợp phục vụ cho chẩn đoán và điều trị sớm cũng như tiên lượng được các biến chứng.

\section{II. ĐỐI TƯƠ'NG VÀ PHƯƠNG PHÁP NGHIÊN CỨU}

2.1 Đối tượng nghiên cứu: các bệnh nhân được chẩn đoán ngộ độc cần sa và cần sa tổng hợp điều trị tại Trung tâm Chống độc Bệnh viện Bạch Mai từ 2/2020 đến 8/2021.

2.1.1 Tiêu chuẩn chọn bênh nhân. Chẩn đoán ngộ độc cấp khi có $2 / 3$ tiêu chuẩn (theo tiêu chuẩn Nguyễn Thị Dụ)

1) Bệnh sử có sử dụng cần sa hoặc cần sa tổng hợp

(2) Có triệu chứng của ngộ độc
(3) Xét nghiêm độc chất (trong nước tiểu và trong bệnh phẩm bệnh nhân sử dụng) dương tính với cần sa hoặc cần sa tổng hợp

2.1.2 Tiêu chuẩn loại trừ. Bệ̂nh nhân ngộ độc đồng thời các loại ma túy khác

\subsection{Thời gian địa điểm nghiên cứu:}

Thời gian nghiên cứu: từ tháng 2/2020 đến tháng 8/2021

Địa điểm nghiên cứu: Trung tâm chống độc bệnh viện Bạch Mai

2.3 Phương pháp nghiên cứu. nghiên cứu mô tả tiến cứu

2.4 Cõ̃ mẫu nghiên cứu: tất cả bệnh nhân vào điều trị tại Trung tâm chống độc trong thời gian nghiên cứu phù hợp với tiêu chuẩn chọn, có 48 bệnh nhân đủ tiêu chuẩn

\subsection{Tiến hành nghiên cứu}

- Lựa chọn những bệnh nhân đủ tiêu chuẩn nghiên cứu

- Thu thập số liệu theo bệnh án nghiên cứu thống nhất

- Thông tin chung: tuổi, giới, nghề nghiệp,

- Hoàn cảnh xảy ra ngộ độc (lạm dụng, tai nạn)

- Dạng chất bệnh nhân sử dụng (dạng thảo mộc, thuốc lá điện tử, tinh dầu, bánh...), Hình thức sử dụng (hút, nhỏ dưới lưỡi, ăn , uống...)

- Thời điểm đến viện, thời gian xuất hiện triệu chứng tính từ lúc tiếp xúc với chất độc đến lúc xuất hiện triệu chứng đầu tiên.

- Đánh giá các triệu chứng khởi phát, các biểu hiện lâm sàng, cận lâm sàng

- So sánh một số chỉ số giữa 2 nhóm cần sa và cần sa tổng hợp

2.6 Phương pháp xử lý số liệu. các số liệu được phân tích theo phương pháp thông kê y học, trên chương trính SPSS 20.0 tính tỷ lệ \%, trung bình \pm độ lệch chuẩn, so sánh trung bình bằng $\mathrm{t}$ test, so sánh tỷ lệ $\%$ bằng $\mathrm{X}^{2}$ (hoặc Fisher exeact test). Khác biệt có ý nghĩa thống kê khi giá trị kiểm định $\mathrm{p}<0.05$.

\section{KẾT QUẢ NGHIÊN CỨU}

Trong khoảng thời gian từ 2/2020 đến 8/2021 có 48 bệnh nhân ngộ độc cần sa, cần sa tổng hợp đủ tiêu chuẩn chọn vào nghiên cứu.

3.1 Đăc điểm chung của đối tượng nghiên cứu. Trong quần thể nghiên cứu nam giới chiếm chủ yếu $39 / 48$ bệnh nhân $(81,3 \%)$ nữ 9/48 bệnh nhân (18,8\%). Tuổi trung bình của nhóm nghiên cứu 28,1 $\pm 11,5$ (nhỏ nhất 13 tuổi, lớn nhất 61 tuổi), nhóm tuổi (19-29) gặp nhiêu nhất $47,9 \%$, tiếp đến là nhóm $(30-39)$ tuổi $20,8 \%$. Nghề nghiệp: học sinh sinh viên là đối tượng thường gặp (34,5\%), sau đây là nhóm lao 
động tự do (31,3\%). Lý do ngộ độc nhiều nhất: lạm dụng $(97,9 \%)$, tai nạn $(2,1 \%)$. Thời gian trung bình xuất hiện triệu chứng ngộ độc $9 \pm 6,6$ phút. Dạng chất sử dụng đa dạng trong đó hay gặp dạng sợi thực vật (54,2\%), tiếp theo là thuốc lá điện tử $(31,3 \%)$, dạng tinh dầu $(12,5 \%)$, bánh $(2,1 \%)$. Hình thức sử dụng: hút thuốc $(85,5 \%)$ nhỏ dưới lưỡi $8,3 \%$, ăn uống $(4,2 \%)$, xịt họng $(2,1 \%)$. Các loại cần sa tổng hợp định danh được ADB-Butinaca 5 BN $(10,41 \%)$, MDMB-4en-PINACA 8 BN (16,6 \%), 4F-ABUTINACA 2 BN (4,16\%), 5F MDMB PICA 2 BN (4,16\%).

\section{2 Đặc điểm lâm sàng}

\section{Bảng 1: Các triệu chứng xuât hiện trước khi vào viện}

\begin{tabular}{|c|c|c|c|c|c|c|c|}
\hline Triệu chứng & \multicolumn{2}{|c|}{ THC } & \multicolumn{2}{c|}{ CSTH } & \multicolumn{2}{c|}{ Tống } & \multirow{2}{*}{ P } \\
\cline { 2 - 7 } & Số BN & $\mathbf{\%}$ & Số BN & $\mathbf{\%}$ & Số BN & \% & \\
\hline $\begin{array}{c}\text { Chóng mặt, mất điêuu hòa hoă̆c giảm } \\
\text { khả năng phối hợp động tác }\end{array}$ & 11 & 22,9 & 20 & 41,7 & 31 & 64,6 & 0,433 \\
\hline Buồn nôn,nôn & 4 & 8,3 & 9 & 18,8 & 13 & 27,1 & 0,447 \\
\hline Giảm ý thức, ngất & 3 & 6,2 & 13 & 27,1 & 16 & 33,3 & 0,037 \\
\hline Co giật & 4 & 8,3 & 6 & 12,5 & 10 & 20,8 & 1,0 \\
\hline Khón thở & 8 & 16,7 & 9 & 18,8 & 17 & 35,4 & 0,433 \\
\hline Ao thanh & 5 & 10,4 & 17 & 35,4 & 22 & 45,8 & 0,028 \\
\hline Ao thị & 5 & 10,4 & 17 & 35,4 & 22 & 45,8 & 0,028 \\
\hline Kích động & 6 & 12,5 & 17 & 35,4 & 23 & 47,9 & 0,067 \\
\hline Hoang tưởng bị hại & 3 & 6,2 & 5 & 10,4 & 8 & 16,7 & 1,0 \\
\hline
\end{tabular}

Nhận xét: các triệu chứng của hệ thần kinh xuất hiện sớm và nhiều nhất chóng mặt, mất điều hòa hoặc giảm khả nắng phối hợp động tác 31 bệnh nhẩn $(64,6 \%)$ ngất 16 bệnh nhân $(33,3 \%)$, co giật 10 bệnh nhân $(20,8 \%)$ tiếp đến triệu chứng của hệ tâm thân: kích động 23 bệnh nhân $(47,4 \%)$ ảo thanh, ảo thị $45,8 \%$. Các triệu chứng của nhóm ngộ độc cần sa tổng hợp xu hướng xuất hiện nhiều, rầm rộ hơn, sự khác biệt có ý nghĩa thống kê ở nhóm triệu chứng ngất và triệu chứng hệ tâm thần.

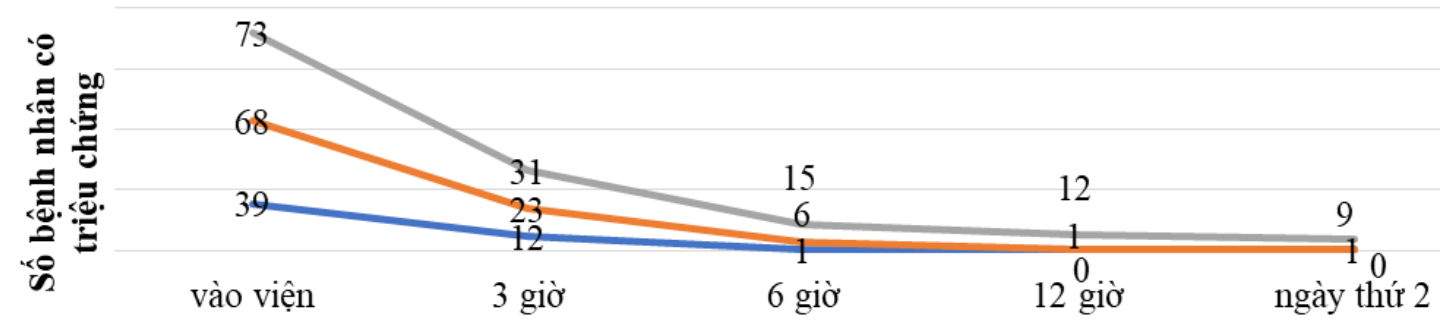

—hệ tim mạch — - hệ thần kinh — - Thệ tâm thần gian

Biểu đồ 1: Diễn biến triệu chứng theo thời gian của các hê cơ quan

Nhận xét: Các triệu chứng lâm sàng giảm sau 3 giờ điều trị, thường hết vào giờ thứ 6 , Các triệu chứng của hệ tâm thần kéo dài hơn so với các cơ quan khác.

3.3 Đặc điểm cận lầm sàng

Bảng 2: Đặc điểm khí máu bệnh nhân lúc vào viện

\begin{tabular}{|c|c|c|c|c|}
\hline Thông số & THC (N=19) & CSTH (N= 28) & Chung (N = 47) & P \\
\hline Toan chuyến hóa & $2(4,3 \%)$ & $4(8,5 \%)$ & $6(12,8 \%)$ & 1,0 \\
\hline Kiềm hô hấp & $4(8,5)$ & $4(8,5 \%)$ & $8(17 \%)$ & 0,69 \\
\hline Bình thường & $13(27,7 \%)$ & $20(42,6 \%)$ & $33(70,2 \%)$ & 0,82 \\
\hline Tăng lactac & $4(8,5 \%)$ & $6(12,8 \%)$ & $10(21,3 \%)$ & 1,0 \\
\hline Toan hô hấp & 0 & 0 & 0 & \\
\hline Kiềm chuyến hóa & 0 & 0 & 0 & \\
\hline
\end{tabular}

Nhận xét: 33 BN (70,2\%) có khí máu bình thường, 8 BN (17\%) kiềm hô hấp chia đều cho 2 nhóm, 6 BN $(12,8 \%)$ toan chuyển hóa tăng lactac máu ở bệnh nhân co giật trong đó THC 2 bệnh nhân (4,3\%) nhóm CSTH 4 bệnh nhân $(8,5 \%) .10 \mathrm{BN}(21,3 \%)$ có tăng lactac máu ở thời điểm nhập viện. nhóm CSTH có xu hướng xuất hiện biến đổi khí máu nhiều hơn so với THC sự khác biệt chưa có ý nghĩa thống kê. 


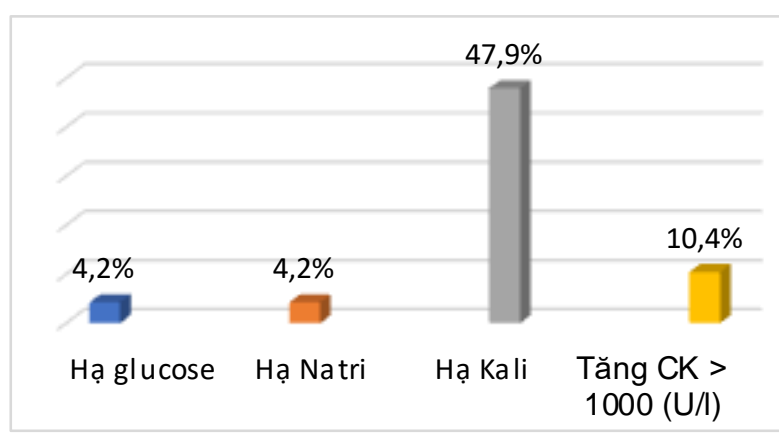

Biểu đồ 2: Tân suất thay đổi các triệu chứng trên sinh hóa máu

Nhân xét: Triệu chứng thường gặp ha Kali máu 23 bệnh nhân (47,9\%), CK > 1000 (U/L) có 5 bệnh nhân chiếm $10,4 \%$, Hạ glucose và Natri máu giảm gặp $4,2 \%$ mối nhóm.

Bảng 3: Đăc điểm điên tim lúc vào viên

\begin{tabular}{|c|c|c|}
\hline Triệu chứng & Số BN & Tỷ lệ \% \\
\hline Nhịp nhanh xoang & 17 & 35,4 \\
\hline Loạn nhịp xoang & 1 & 2,1 \\
\hline Nhịp chậm xoang & 1 & 2,1 \\
\hline Bình thường & 29 & 60,4 \\
\hline
\end{tabular}

Nhận xét: Trong nhóm nghiên cứu làm điện tâm đổ tại thời điểm vào viện rối loạn điện tịm thường gặp nhất là nhịp nhanh xoang $17 \mathrm{BN}$ $(35,4 \%)$, nhịp chậm xoang $1 \mathrm{BN}(2,1 \%)$ và loạn nhịp xoang $1 \mathrm{BN}(2,1 \%)$ cả 2 bệnh nhân này đều thuộc nhóm cần sa tổng hợp.

\section{BÀN LUÂN}

Đặc điểm lâm sàng: Trong nghiên cứu của chúng tôi trên 48 bệnh nhân ngộ độc cần sa, cần sa tổng hợp độ tuổi trong nghiên cứu từ (13 61) tuổi, nhóm tuổi mắc nhiều nhất là nhóm từ (19-29) tuổi với tỷ lệ 47,9\% với độ tuổi trung bình là 28 tuổi tương tự với nghiên cứu của Juliana Tournebize và cộng sự với độ tuổi mắc của ngộ độc cần sa tổng hợp là $(14-25)$ tuổi với độ tuổi trung bình là $24,5 \pm 10,1$ tuổi ${ }^{3}$, tương tự với nghiên cứu của Matthew J. Noble tuổi trung bình 20 tuổi, độ tuổi nghiên cứu (8 tháng 96 tuổi $)^{4}$. Đặc điểm về giới tính của bệnh nhân trong nghiên cứu chúng tôi gặp chủ yếu bệnh nhân là nam giới với tỷ lệ $81,3 \%$, nữ giới chiếm tỷ lệ $18,8 \%$. Tương đồng với nghiên cứu của tương đồng với nghiên cứu của Christopher 0 Hoyte tuổi trung bình là $22,5 \pm 8,8$. Nam giới chiếm $74,3 \%{ }^{5}$. Học sinh sinh viên là đối tượng thường gặp $(34,5 \%)$, nhóm lao động tự do (31,3\%). Lý do ngộ độc nhiều nhất: lạm dụng $(97,9 \%)$, tai nạn $(2,1 \%)$, dạng chất hay gặp dạng sợi thực vật $(54,2 \%)$, tiếp theo là thuốc lá điện tử $(31,3 \%)$, dạng tinh dầu $(12,5 \%)$, bánh
$(2,1 \%)$. Hình thức sử dụng: hút thuốc $(85,5 \%)$, nhỏ dưới lưỡi $8,3 \%$, ăn uống $(4,2 \%)$, xịt họng $(2,1 \%)$. Các loại cần sa tổng hợp phát hiện được trong mẫu bệnh phẩm bệnh nhân sử dụng và trong nước tiểu ADB-Butinaca $5 \mathrm{BN}(10,41 \%)$, MDMB-4en-PINACA 8 BN (16,6\%), 4F-ABUTINACA 2 BN $(4,16 \%)$, 5F MDMB PICA 2 BN (4,16\%).

Trong nghiên cứu của chúng tôi triệu chứng nhiễm độc thần kinh, tâm thần là thường gặp, các triệu chứng của hệ thần kinh xuất hiện sớm và nhiều nhất chóng mặt, mất điều hòa hoặc giảm khả năng phối hợp động tác 31 BN $(64,6 \%)$ giảm ý thức, ngất 16 bệnh nhân $(33,3 \%)$, co giật 10 bệnh nhân (20,8\%). Các triệu chứng của hệ tâm thần: kích động $23 \mathrm{BN}$ (47,4\%) ảo thanh, ào thị 45,8\%, Các triệu chứng của nhóm ngộ độc CSTH xu hướng xuất hiện nhiều triệu chứng nặng nguy hiểm tính mạng và râm rộ hơn. Phần lớn các triệu chứng hết sau 6 giờ điều trị.

Đặc điểm cận lâm sàng. Trong nghiên cứu của chúng tôi biến đổi sinh hóa máu hay gặp nhất là Hạ kali máu 23 bệnh nhân $(47,9 \%)$, tăng CK > 1000(U/I) có 5 bệnh nhân chiếm 10,4\%.

$33 \mathrm{BN}(70,2 \%)$ có khí máu bình thường, $8 \mathrm{BN}$ (17\%) kiềm hô hấp chia đều cho 2 nhóm, $6 \mathrm{BN}$ $(12,8 \%)$ toan chuyển hóa tăng lactac máu ở bệnh nhân co giật trong đó THC 2 bệnh nhân (4,3\%) nhóm CSTH 4 bệnh nhân (8,5\%). 10 BN $(21,3 \%)$ có tăng lactac máu ở thời điểm nhập viện. nhóm CSTH có xu hướng xuất hiện biến đổi khí máu nhiều hơn so với THC.

Rối loạn điện tim thường gặp nhất là nhịp nhanh xoang 17 BN $(35,4 \%)$, nhịp chậm xoang 1 $\mathrm{BN}(2,1 \%)$ và loạn nhịp xoang $1 \mathrm{BN}(2,1 \%)$ cả 2 bệnh nhân này đều thuộc nhóm CSTH.

\section{KẾT LUẬN}

Ngộ độc cấp THC và CSTH là vấn đề thường gặp với nhiều biểu hiện lâm sàng về thần kinh, tâm thần, tim mạch, hô hấp khác nhau.Trong những năm gần đây, sử dụng cần sa tổng hợp ngày càng phổ biến, đặc biệt hay gặp ở đối tượng trẻ tuổi, với các triệu chứng lâm sàng về thần kinh, tâm thần như (giảm ý thức, kích động, lo lắng, hoang tưởng, ảo giác, co giật). Trường hợp đến cơ sở y tế muộn và không xử trí đúng có thể gây ra các biến chứng nặng nề như tiêu cơ vân, suy thận cấp, toan chuyển hóa, suy hô hấp, Hạ kali máu, rối loạn nhịp tim làm tăng nguy cơ tử vong. Xét nghiệm định tính, định lượng nồng độ THC và CSTH có rất nhiều khó khăn và hạn chế nên không được sử dụng rộng rãi và kịp thời trong điều trị ngộ độc. Do đó việc 
xác định các triệu chứng lâm sàng, cận lâm sàng đóng vai trò quan trọng giúp chẩn đoán đúng, điều trị kịp thời cũng như hạn chế các biến chứng.

\section{TÀI LIÊU THAM KHẢO}

1. WHO Cannabis. WHO. https:// www.who.int/substance_abuse/facts/cannabis/en/. Accessed May 5, 2020.

2. Sharma $P$, Murthy $P$, Bharath MMS. Chemistry, Metabolism, and Toxicology of Cannabis: Clinical Implications. Iran J Psychiatry. 2012;7(4):149-156.
3. Tournebize J, Gibaja V, Kahn JP. Acute effects of synthetic cannabinoids: Update 2015. Subst Abuse. 2017;38(3):344-366. doi:10.1080/ 08897077.2016.1219438

4. Noble MJ, Hedberg K, Hendrickson RG. Acute cannabis toxicity. Clin Toxicol. 2019;57(8):735742. doi:10.1080/15563650.2018.1548708

5. Hoyte CO, Jacob J, Monte AA, Al-Jumaan $M$ Bronstein AC, Heard $\mathrm{KJ}$. A characterization of synthetic cannabinoid exposures reported to the National Poison Data System in 2010. Ann Emerg Med. 2012;60(4):435-438. doi:10.1016/ j.annemergmed.2012.03.007.

\title{
NGHIÊN CỨU BÀO CHẾ VIÊN NANG LỤC VỊ ĐİA HOÀNG
}

\author{
Nguyễn Văn Hưng ${ }^{1}$, Lê Thị Minh Nguyệt ${ }^{1}$, Lê Thị Khánh Ly ${ }^{1}$, \\ Đỗ Nguyễn Hạnh Phước ${ }^{1}$, Lê Nguyễn Bảo Thi ${ }^{1}$, Trần Văn Trọng ${ }^{1}$, \\ Nguyễn Thế Dũng ${ }^{1}$, Phạm Hoàng Đức ${ }^{1}$
}

\section{TÓM TẮT}

Mục tiêu: Xây dựng qui trình bào chế viên nang Lục vị địa hoàng và đánh giá chất lượng sản phẩm bào chế. Đối tướng và phương pháp nghiên cứu: Bài thuốc Lục vị địa hoàng; phương pháp: khảo sát thời gian sắc đế bào chế cao, khảo sát tỷ lệ tá dược để bào chế viên nang Lục vị địa hoàng và đánh giá chất lương sản phẩm. Kểt quả: Cao Luc vi đia hoàng được điêu chế bằng phương pháp sắc trong thời gian 60 phút. Viên nang Lục vị đia hoàng chứa $150 \mathrm{mg}$ cao phối hợp với Lactose, Tinh bột, Magnesi stearate, Aerosil và đat các qui chuẩn chẩt lương qui định. Kết luận: Đã nghiên cứu bào chế được viên nang Lục vị hoàn làm cơ sở cho việc nghiên cứu sâu hớn nhằm phát huy các giá trị của bài thuốc Y học cổ truyền.

Từ khóa: "Lục vị địa hoàng", viên nang, độ rã, độ ẩm.

\section{SUMMARY}

\section{STUDY ON PREPARATION OF "LUC VI DIA} HOANG" CAPSULES

Objectives: To develop a process for preparing Luc vi dia hoang capsule and evaluate the quality of prepared products. Subjects and Methods: "Luc vi dia hoang" remedy, surveying the high preparation time, surveying the proportion of excipients for preparing Luc vi dia hoang capsules and evaluating product quality. Results: Luc vi dia hoang condensed status was prepared by the decoction method in 60 minutes. Luc vi dia hoang capsule contains $150 \mathrm{mg}$ active substance combined with Lactose, Starch, Magnesi stearate, Aerosil and meets the specified quality standards. Conclusion: Research has been made to prepare the capsule of Luc vi dia hoang as

${ }^{1}$ Trường Đại hoc Y - Dượ, Đai hoc Huế Chịu trách nhiệm chính: Nguyễn Văn Hưng Email: nvhung.yhct@huemed-univ.edu.vn Ngày nhân bài: 11.8 .2021

Ngày phản biên khoa hoc: 11.10.2021

Ngày duyệt bài: 18.10 .2021 the basis for further research in order to promote the values of traditional medicine.

Keywords: "Luc vi dia hoang", capsules, disintegration, moist.

\section{I. ĐĂT VẤN ĐỀ}

Theo Y học cổ truyền (YHCT) nguồn gốc bênh tật phát sinh là do mất cân bằng âm dương [7]. Vì vậy nguyên lý điều trị theo YHCT là lập lại cân bằng âm dương trong cơ thể, nâng cao sức khoẻ. Thuốc YHCT cũng được sử dụng dựa trên mục đích điều hoà cân bằng âm dương. Việc bào chế và sử dụng thuốc YHCT đa dạng, phong phú; thông qua việc bào chế có thể làm tăng tác dụng điều trị của các vị thuốc và bài thuốc. Bài thuốc "Lục vị địa hoàng" là bài thuốc cổ phương của Đại danh Y Trương Trọng Cảnh có tác dụng điều chỉnh, tư bổ phần âm của cơ thể [3], [5], [6]. Ở Việt Nam đại danh y Hải Thượng Lãn Ông cũng đã ứng dung bài thuốc Lục vi đia hoàng làm nền tảng cắn bản để điều trị nhiều bệnh lý khác nhau. Hiện nay, bài thuốc Lục vị địa hoàng được ứng dụng rộng rãi trên lâm sàng và được sử dụng dưới nhiều dạng khác nhau như thuốc sắc, thuốc hoàn [4]. Các dạng bào chế khác nhau của các bài thuốc $Y$ học cổ truyền sẽ làm đa dạng, phong phú các chế phẩm trên thị trường đáp ứng nhu cầu chăm sóc sức khoẻ của nhân dân. Để góp phần phát huy các giá trị của bài thuốc, việc áp dụng các dang bào chế thích hợp để thuận tiện cho người sử dụng nhằm nâng cao hiệu quả điều trị là vấn đề cần được quan tâm [1], [2]. Viên nang là dạng bào chế có nhiều ưu điểm như gọn, nhỏ, dễ sử dụng, có sinh khả dụng cao, che dấu được mùi vị khó chịu của dược liệu.... Trên cơ sở đó, chúng tôi tiến hành 